\title{
PREVALENCIA DE Neospora caninum EN BOVINOS DE UNA EMPRESA GANADERA DE LA SIERRA CENTRAL DEL PERÚ
}

\author{
Nidia Puray Ch. ${ }^{1}$, Amanda Chávez V. ${ }^{2,3}$, Eva Casas A. ${ }^{2}$, \\ Néstor Falcón $\mathbf{P}^{4}{ }^{4}$ y Gina Casas V. ${ }^{2}$
}

\section{AbSTRaCT}

Neosporosis has become a parasitosis of economic importance for dairy cattle due to abortions and neonatal mortality. The study was conducted in 2003 to determine the prevalence of Neospora caninum in cattle of the SAIS Pachacutec farm, located in the highlands of Peru. In total, 347 sera samples were collected from Brown Swiss adult cows. Samples were evaluated through the indirect fluorescent antibody test (IFAT). Results indicated that $12.4 \pm 3.5 \%$ (45/347) of the animals presented antibodies against $N$. caninum (corrected prevalence: $13.2 \pm 3.5 \%$ ). The minimum and maximum seroprevalence was 2.5 and $19.6 \%$ in the 7 sampled herds, without statistical differences. All herds had at least one positive animal. The results confirmed the existence of a moderate prevalence of $N$. caninum in the studied area.

Key words: neosporosis, cow, IFAT, prevalence, antibody

\section{Resumen}

La neosporosis es una parasitosis que afecta el rendimiento económico del sector ganadero al ocasionar abortos y mortalidad neonatal. El objetivo del presente trabajo fue determinar la prevalencia de Neospora caninum en vacas de la empresa de Sociedad Agrícola de Interés Social (SAIS) Pachacutec, ubicada en el departamento de Junín, en el año 2003. Se evaluaron 347 muestras de suero, recolectadas de vacas Brown Swiss adultas, mediante la prueba de inmunofluorescencia indirecta (IFI). El 12.4 $\pm 3.5 \%$ (45/ 347) de los animales presentaron anticuerpos contra el parásito (prevalencia corregida: $13.2 \pm 3.5 \%$ ). Se observó una frecuencia mínima de $2.5 \%$ y una máxima de $19.6 \%$ en los siete hatos evaluados, sin encontrar diferencia estadística significativa. En todos los hatos se encontró, por lo menos, un animal positivo a este parásito. Estos resultados confirman la existencia de una prevalencia moderada de $N$. caninum en la zona estudiada.

Palabras clave: neosporosis, vaca, IFI, prevalencia, anticuerpos

\footnotetext{
${ }^{1}$ Práctica privada

${ }^{2}$ Laboratorio de Microbiología y Parasitología Veterinaria, FMV-UNMSM

${ }^{3}$ E-mail: a_chavez_g@hotmail.com

${ }^{4}$ Laboratorio de Medicina Veterinaria Preventiva, FMV-UNMSM
} 


\section{INTRODUCCIÓN}

La neosporosis es considerada como una de las enfermedades parasitarias que causa grandes pérdidas económicas al sector ganadero a nivel mundial. Su agente, Neospora caninum, es un protozoo que ha adquirido gran importancia al estar implicado como uno de los principales patógenos causantes de aborto en el ganado vacuno. En la actualidad, $N$. caninum se clasifica dentro del phylum Apicomplexa y se relaciona estrechamente con Toxoplasma gondii por la similitud de sus características morfológicas, aunque son antigénicamente diferentes.

La enfermedad no produce signos clínicos visibles en el ganado vacuno con excepción del aborto (Anderson et al., 1997). El aborto es considerado el efecto más adverso de la infección, y los mayores índices ocurren entre el tercer y sexto mes de gestación, afectando la eficiencia reproductiva. Además, afecta a una amplia gama de mamíferos que actúan como hospederos intermediarios que se infectan al consumir agua y alimentos contaminados con ooquistes que se encuentran en las heces de perros infectados (Basso et al., 2001a).

En el Perú, estudios realizados en el ganado bovino registran la presencia de $N$. caninum con prevalencias que varían entre el 30 al 57\% en las cuencas lecheras de Lima y Arequipa (Andresen, 1999; Silva et al., 2002). La mayoría de estas investigaciones se han realizado en explotaciones lecheras de tipo intensivo; sin embargo, en la zona andina, donde la crianza de ganado es de tipo extensivo o mixta, sólo existe un estudio en la Sierra Sur (Atoccsa et al., 2005), donde se encontró una prevalencia de $18 \%$. Faltan estudios que demuestren la existencia de $N$. caninum en bovinos de las diferentes regiones del Perú, así como su impacto en otras especies de mamíferos. Por lo tanto, se diseñó el presente estudio para determinar la pre- valencia de $N$. caninum en bovinos de una Empresa de Sociedad Agrícola de Interés Social (SAIS) en el departamento de Junín, mediante la detección de anticuerpos séricos utilizando la técnica de inmunofluorescencia indirecta, a fin de aportar información para futuros estudios epidemiológicos relacionados a este parásito.

\section{Materiales y Métodos}

\section{Ubicación del estudio}

El muestreo se realizó en la Unidad de Producción Corpacancha, perteneciente a la empresa de Sociedad Agrícola de Interés Social (SAIS) Pachacutec, ubicada en el distrito de Marcapomacocha, provincia de Yauli, departamento de Junín, a una altitud de 4,280 msnm.

\section{Muestras y tamaño muestral}

Las muestras fueron obtenidas entre los meses de marzo a abril del 2003. Se tomaron muestras de sangre por punción de la vena yugular a 347 vacas en producción. El suero se extrajo por centrifugación y fue conservado a temperatura de congelación $\left(-20{ }^{\circ} \mathrm{C}\right)$ hasta el día de su procesamiento.

El tamaño muestral se determinó mediante el método de muestreo aleatorio simple, considerando una prevalencia referencial de $40.4 \%$ (Quevedo et al., 2003) y un nivel de confianza de $90 \%$ (Miguel, 1982).

\section{Determinación de anticuerpos}

Se utilizó la técnica de inmunofluorescencia indirecta (IFI) para la determinación de anticuerpos contra $N$. caninum. El suero fue considerado positivo al observarse fluorescencia completa del taquizoíto, mientras que la muestra fue negativa cuando no se apreció la fluorescencia o cuando se presentó en forma parcial -apical- (Paré et al., 1995). 
Cuadro 1. Prevalencia de Neospora caninum en vacas de la comunidad de Corpacancha, SAIS Pachacutec, Junín (2003)

\begin{tabular}{lcccc}
\hline Hatos & $\begin{array}{c}\text { Animales } \\
\text { muestreados }\end{array}$ & $\begin{array}{c}\text { Animales } \\
\text { positivos }\end{array}$ & $\begin{array}{c}\text { Prevalencia } \\
\% \pm \text { IC }\end{array}$ & $\begin{array}{c}\text { Prevalencia } \\
\text { corregida } \\
\% \pm \text { IC }\end{array}$ \\
\hline Capcash & 40 & 1 & 02.5 & 02.6 \\
Picuycancha & 55 & 6 & 10.9 & 11.2 \\
Cuspicancha & 54 & 6 & 11.1 & 11.4 \\
Ordenal & 46 & 9 & 19.6 & 20.2 \\
Tintán & 45 & 8 & 17.8 & 18.3 \\
Pariacancha & 52 & 5 & 09.6 & 09.9 \\
Ucrucancha & 55 & 10 & 18.2 & 18.9 \\
\hline Total & 347 & 45 & $12.8 \pm 3.5$ & $13.2 \pm 3.5$ \\
\hline
\end{tabular}

\section{Análisis de datos}

Se determinó la prevalencia de $N$. caninum mediante la fórmula de Thrusfield (1990) y el intervalo de confianza con la fórmula de Armitage y Berry (1997). Se utilizó la prueba de Regresión Logística para cuantificar la relación entre la variable hato y la respuesta serológica usando el programa SPSS v. 10.0 .

\section{Resultados Y Discusión}

En el Cuadro 1 se aprecia que la prevalencia hallada fue de $12.8 \pm 3.5 \%(45 / 347)$ y la prevalencia corregida fue de $13.2 \pm 3.5 \%$, con un $98 \%$ de sensibilidad y $99 \%$ de especificidad (Packman et al., 1998) con la prueba serológica de IFI. Esta prevalencia indica que los animales estuvieron expuestos a $N$. caninum en algún momento de sus vidas. Otros estudios realizados en las principales cuencas lecheras del país presentan frecuencias de 29 a 57\% (Andresen, 1999; Silva et $a l . ; 2002$ ), indicando que el presente resulta- do fue inferior, por lo que se le considera como una prevalencia moderada.

La frecuencia de presencia de anti-cuerpos contra $N$. caninum en los hatos bajo evaluación fue variable aunque sin diferencias estadísticas entre ellos (Cuadro 1), posiblemente debido a que muchos de los animales habían rotado entre los diversos hatos con el paso del tiempo al ir variando su estado reproductivo y nivel de producción láctea. Se detectó la presencia de, al menos, un animal positivo en cada hato, de allí que la variable hato no constituiría un factor de riesgo.

La prevalencia moderada encontrada podría estar favorecida por el tipo de manejo que realiza la SAIS Pachacutec, el cual se caracteriza por realiazar una crianza extensiva, donde los animales se encuentran separados por especies productivas; es decir, no se produce una crianza mixta como ocurre con otros centros de producción de la sierra sur y central. Además, la introducción de animales nuevos es bastante limita$\mathrm{da}$, pudiendo de esa forma restringirse el ingreso de animales infectados. Sin embargo, 
se tiene conocimiento que tiempo atrás, la empresa realizó la importación de vacas de raza Simmental, y es posible que ésta haya sido la vía de ingreso del parásito a la empresa.

Se sabe que la difusión de la enfermedad se encuentra influenciada por la introducción de animales en forma clandestina o por importación. Los estudios de Quevedo et al. (2003) en bovinos de la zona de Amazonas reportan una prevalencia de $40 \%$, posiblemente debido al comercio clandestino de animales. De igual manera, un estudio en Turquía demostró el riesgo que representó la importación de animales para la difusión de la neosporosis en el ganado bovino (Akca et al., 2005).

Otro aspecto a considerar es el trabajo de prevención de enfermedades que realiza la empresa SAIS Pachacutec, ya que tiene como política sanitaria la tenencia de un máximo de 2-3 perros jóvenes por hato, con el fin de controlar la difusión de la hidatidosis en la población ovina. Además, la empresa obliga a sus trabajadores a entregar todo animal muerto para su posterior destrucción, evitando de esta manera el consumo de carne cruda por los cánidos. En estudios realizados por Paré et al. (1998) y Basso et al. (2001b), se demuestra que la existencia de tres o más perros por hato constituye un factor de riesgo para la ocurrencia de abortos en el ganado vacuno. Además, se conoce que la seroprevalencia a $N$. caninum en perros se incrementa con la edad, favoreciéndose la transmisión horizontal en el ganado (Basso et al., 2001a). Por otro lado, se conoce que los niveles de anticuerpos en perros de áreas rurales son mayores que en áreas urbanas (Patitucci et al., 2001; Wouda et al., 1999).

Un factor de riesgo que estaría involucrado en el incremento de la prevalencia de $N$. caninum sería la presencia de animales portadores. Davison et al. (1999) señalaron la transmisión vertical como una vía de transmisión para el mantenimiento de la infección; así mismo, Williams et al. (2003) demostraron que vacas infectadas crónicamente transmiten el parásito a través de la placenta, y que los fetos pueden ser abortados o quedar congénitamente infectados. Esta situación se puede repetir en varias gestaciones y algunas vacas pueden abortar más de una vez; comprobándose que el parásito se mantiene en ausencia del hospedero definitivo.

En la SAIS Pachacutec, la crianza es "cerrada"; donde las hembras de reemplazo provienen del mismo rebaño y sólo los machos son sustituidos para el mejoramiento genético, por lo que en cada hato se puede hallar de 2 a 3 toros para que realicen la monta natural. Estudios realizados por Ortega-Mora et al. (2003) y Caetano da Silva et al. (2004) encontraron toros seropositivos a $N$. caninum, motivo por el cual ambos autores señalan que no se debe descartar la transmisión venérea.

Los resultados de este estudio sólo indicarían una exposición natural de los vacunos a $N$. caninum y que la infección se encuentra presente en el departamento de Junín. Los resultados obtenidos no pueden ser asociados necesariamente con la presencia de abortos o enfermedad, debido, principalmente, a la falta de registros que permitan evaluar la eficiencia reproductiva.

\section{Conclusiones}

- La infección con $N$. caninum se encuentra presente en las vacas de la SAIS Pachacutec, registrándose una seropositividad moderada de $12.8 \pm 3.5 \%$.

- Todos los hatos en estudio presentaron, al menos, un animal seroreactor, pero no se puede afirmar que el parásito es el causante de los problemas reproductivos de la zona. 


\section{Literatura Citada}

1. Akca, A.; H. Gokce; C. Guy; J. McGarry; D. Williams. 2005. Prevalence of antibodies to Neospora caninum in local and imported cattle breeds in the Kars province of Turkey. Res. Vet. Sci. 78: 123-126.

2. Anderson, M.L.; J.P. Reynolds; J.D. Rowe; K. Sverlow; A. Packham; B. Barr; P. Conrad. 1997. Evidence of vertical transmission of Neospora sp. infection in dairy cattle. J. Am. Vet. Med. Assoc. 210: 1169-1172.

3. Andresen, H. 1999. Neosporosis en el Perú y el mundo. Rev. Cienc. Vet. 15: 11-16.

4. Armitage, P.; G. Berry. 1997. Statistical methods in medical research. $2^{\text {nd }} e d . p$ 115-120. Blackwell Scientific. U.K.

5. Atocsa, J.; A. Chávez; E. Casas; N. Falcón. 2005. Seroprevalencia de Neospora caninum en vacunos lecheros criados al pastoreo en la provincia de Melgar, departamento de Puno. Rev. Inv. Vet., Perú 15: 71-75.

6. Basso, W.; L. Venturini; M. Venturini; D. Hill; O. Kwok; S. Shen; J. Dubey. 2001a. First isolation of Neospora caninum from the feces of a naturally infected dog. J. Parasitol. 87: 612-618.

7. Basso,W.; L. Venturini; M. Venturini; P. Moore; M. Rambeau; J. Unzaga; C. Campero; D. Bacigalupe; J. Dubey. 2001b. Prevalence of Neospora caninum infection in dogs from beef cattle farms, dairy farms, and from urban areas of Argentina. J. Parasitol. 87: 906-907.

8. Caetano-da-Silva, A.; I. Ferre; G. Aduriz; G. Álvarez; I. del-Pozo; R. Atxaerandio; J. Regidor-Cerrillo; $C$. Ugarte-Garagalza; L. Ortega-Mora. 2004. Neospora caninum infection in breeder bulls: Seroprevalence and comparison of serological methods used for diagnosis. Vet. Parasitol. 124: 19-24.

9. Davison, H.; A. Otter; A. Trees. 1999. Estimation of vertical and horizontal transmission parameters of Neospora caninum infections in dairy cattle. Inter. J. Parasitol. 29: 1683-1689.

10. Miguel, O. 1982. Tecnicas de amostragem para exams laboratorias. Hyg. Alim. 1: 849-856.

11. Ortega-Mora, L.; I. Ferre; I. del Pozo; A. Caetano; E. Collantes; J. Regidor; C. Ugarte; G. Aduriz. 2003. Detection of Neospora caninum in semen of bulls. Vet Parasitol. 117: 301-308.

12. Paré, J.; S. Hietala; M. Thumond. 1995. Interpretation of an indirect fluorescent antibody test for diagnosis of Neospora sp. infection in cattle. J. Vet. Diagn. Invest. 7: 273-275.

13. Packham, A.; K. Sverlow; P. Conrad; E. Loomis; J. Rowe; M. Anderson; A. Marsh; C. Cray; B. Barr. 1998. A modified agglutination test for Neospora caninum: development, optimization, and comparison to the indirect fluorescentantibody test and enzyme-linked immunosorbent assay. Clin. Diagn. Lab. Immunol. 5: 467-473.

14. Pare, J.; G. Fecteau; M. Fortin; G. Marsolais. 1998. Seroepidemiologic study of Neospora caninum in dairy herds. J.A.V.M.A. 213: 1595-1598.

15. Patitucci, A.; M. Phil; M. Perez; M. Rozas; K. Israel. 2001. Neosporosis canina: Presencia de anticuerpos séricos en poblaciones caninas rurales y urbanas de Chile. Arch. Med. Vet. 33: 227232.

16. Quevedo,V.; A. Chávez; H. Rivera; E. Casas; E. Serrano. 2003. Neosporosis en bovinos lecheros en dos distritos de la provincia de Chachapoyas. Rev. Inv. Vet., Perú 14: 33-37.

17. Silva, P.; A. Chávez; H. Rivera; E. Casas. 2002. Seroprevalencia de Neospora caninum en bovinos lecheros del valle de Lima. Rev. Inv. Vet., Perú 13: 51-55.

18. Thrusfield, M. 1990. Epidemiología veterinaria. p 228-230. Ed. Acribia. Zaragoza, España. 
19. Wouda, W; T. Dijkstra; A.M.H. Kramer; C. van Maanen; J.M.A. Brinkhof. 1999. Seroepidemiological evidence for a relationship between Neospora caninum infection in dogs and cattle. Int. J. Parasitol. 29: 1677-1682.
20. Williams, D.J.; C.S. Guy; R. Smith; F. Guy; J. McGarry; J. McKay; A. Trees. 2003. First demonstration of protective immunity against foetopathy in cattle with latent Neospora caninum infection. Int. J. Parasitol. 33: 1059-1065. 